\title{
A meta-analysis of the incidence rate of postoperative acute kidney injury in patients with congenital heart disease
}

\author{
Dandan $\mathrm{Li}^{1}$, Zhaozhuo Niu², Qiang Huang ${ }^{2}$, Wei Sheng ${ }^{2}$ and Tianyi Wang ${ }^{2 *}$
}

\begin{abstract}
Background: Acute kidney injury (AKI) is a common complication of cardiac surgery. However, the incidence rate of AKI in patients with congenital heart disease (CHD) greatly varies between reports owing to the different definitions used for AKI. Therefore, this study was designed as a meta-analysis aimed at summarizing the incidence rate of AKI in patients with congenital heart disease (CHD) on the basis of different AKI criteria.

Methods: Studies published till April 24, 2020, on the incidence rate of AKI in patients with CHD, were retrieved from electronic databases and printed literature. To pool data from the included studies, the effect size, a combined statistics, was chosen and presented with the incidence rate and 95\% confidence interval (Cl). Heterogeneity was evaluated using $P^{2}$ statistics and Cochran $Q$ test. The incidence rates obtained from the subgroup analysis according to study location, type of surgery, type of cohort, age, and AKI criteria) were also evaluated to determine the correlation of AKI with these factors. Publication bias was estimated using the Egger test.

Results: Thirty studies, comprising 9925 patients with AKI who had CHD, were included. Overall, the pooled incidence rate of AKI in the patients with CHD was 38.4\% (95\% Cl, 32.0-44.7\%). However, the incidence rate was not significantly affected by gender, study location, type of surgery, type of cohort, and AKI criteria. Moreover, age was significantly associated with the incidence of AKI, and the incidence rate was higher in the patients aged $<1$ month than in those aged 1 month to 18 years, $<18$ years, and $\geq 18$ years $(P<0.05)$.

Conclusions: In this study, the estimated incidence rate of AKI in patients with CHD was $38.4 \%$ and may be influenced by age. These findings highlight the importance of further investigation of the specific causes of and effective preventive measures for AKI.
\end{abstract}

Keywords: Acute kidney injury, Congenital heart disease, Meta-analysis, Incidence rate

\section{Background}

Congenital heart disease (CHD), the most common type of congenital birth defect, is the major cause of mortality among children $[1,2]$. The prevalence rate of CHD is estimated to be 8 cases per 1000 live births [3]. An estimated $20 \%$ of patients may require surgery during the first 15

\footnotetext{
*Correspondence: hank.titan@163.com

${ }^{2}$ Department of Cardiovascular Surgery, Qingdao Municipal Hospital, No. 5 Donghai Middle Road, Shinan District, Qingdao 266000, Shandong, China Full list of author information is available at the end of the article
}

years of adulthood, of whom $40 \%$ would need reoperations [4]. Despite the marked improvement in survival after cardiac surgery for CHD, the mortality rate in children with CHD treated with after cardiac surgery is $4 \%$ [5]. In addition, in adults, the associated mortality rate increases up to 6 months (2.4\%) after surgery, with an overall 30-day mortality rate of $1.5 \%$ [6].

Postoperative acute kidney injury (AKI), a common complication of cardiac surgery [7], is a clinical syndrome characterized by water, electrolyte, and acid-base 
imbalances, and accumulation of nitrogenous wastes caused by a rapid decrease in glomerular filtration function within hours to weeks [8]. AKI occurs in $2.7-70 \%$ of patients with $\mathrm{CHD}$ who undergo cardiac surgery $[9$, 10]. The inconsistent incidence rates of AKI in patients with CHD may be associated with the differences in patient population, sample size, and AKI identification and classification criteria among studies. In addition, AKI may cause prolonged mechanical ventilation and hospital stay and high morbidity and mortality rates [1114]. Several previous systematic reviews and metaanalyses mainly focused on the incidence rate of AKI in patients who had undergone total hip arthroplasties [15] or cardiac transplantation [16], but no meta-analysis of pooled incidence rates of AKI in patients with $\mathrm{CHD}$ from relevant studies has been reported yet.

Currently, different AKI identification and classification criteria are used in different clinical studies $[17,18]$. Initially, the AKI Network (AKIN) criteria, also known as the modified pediatric Risk, Injury, Failure, Loss, EndStage Kidney Disease (pRIFLE) criteria, were developed on the basis of the pRIFLE criteria with the addition of serum creatinine (SCr) level [19]. The Kidney Disease Improving Global Outcomes (KDIGO) was then proposed, by combining the RIFLE and AKIN criteria, to determine the SCr level and urine output [20]. Studies that reported the epidemiology of AKI greatly varied owing to the different definitions used, and the observations on the incidence rate of AKI were difficult to compare [18]. Thus, this meta-analysis was retrospectively performed to summarize the incidence rate of AKI based on the three AKI criteria in patients with CHD.

\section{Materials and methods}

\section{Search strategy}

PubMed (http://www.ncbi.nlm.nih.gov/pubmed), Embase (http://www.embase.com), and The Cochrane library (http://www.cochranelibrary.com) were chosen for systematic literature retrieval according to the pre-established search strategy. The retrieval keywords included "Acute Kidney Injury," "AKI," "Acute Renal Failure," "ARF," "Congenital Heart Disease," "CHD," and "Congenital Heart Defects." The retrieval time was up to April 24, 2020, without language restrictions. Detailed information on the retrieval steps and results of the database search on PubMed (Supplementary Table 1), Embase (Supplementary Table 2), and The Cochrane Library (Supplementary Table 3) were provided. Furthermore, a manual search for conceivably related studies using the references of the included articles was additionally performed.

\section{Study selection criteria}

The following types of studies were included: (1) those that included subjects with CHD who underwent cardiac surgery without a history of kidney transplantation; (2) those with the incidence rate of AKI as research outcome; (3) those that used the pRIFLE, AKIN, and KDIGO diagnostic criteria for AKI; and (4) prospective or retrospective cohort studies.

The following types of studies were excluded: (1) reviews, letters, or comments, and (2) those that included the latest or most complete information among repeated or multiple studies that used the same data.

\section{Data extraction}

Two investigators (Dandan Li and Zhaozhuo Niu) independently screened the eligible studies using a predesigned data collection form. The following information was included: first author's name, publication year, research region, recruitment time, age, sample size, research type, operation type, and AKI definition. After data extraction, any discrepancies were resolved via discussion with two other investigators (Qiang Huang and Wei Sheng).

\section{Assessment of methodological quality}

The Agency for Healthcare Research and Qualityrecommended scale was applied for the evaluation of the methodological qualities of the included studies [21]. This scale evaluates studies on the basis of an 11-item checklist, with a final score ranging from 0 to 11 points. Studies with scores $<4$, between 4 and 7 , and $>7$ were considered as having low-, moderate-, and high-quality methods, respectively.

\section{Statistical analyses}

All the meta-analyses were performed using Stata version 10.0 (Stata Corporation, College Station, TX, USA). Incidence rates with their 95\% confidence intervals (CIs) were used to evaluate the effect value. The heterogeneity among studies was calculated using the Cochran $Q$ test [22] and $I^{2}$ test [23]. When the $Q$ statistics $P$ value was $<0.05$ or $I^{2}$ value was $>50 \%$, a statistically significant heterogeneity among studies was considered, and a random-effects model of meta-analysis was used to pool the estimates. Otherwise, a fixed-effects model was used. A subgroup analysis was performed according to study location, type of surgery, type of cohort, age, and criteria of AKI to evaluate the correlation between these factors and the study outcome. In addition, the publication bias in the meta-analysis likely led to small-study effects, where the smaller studies might have shown larger treatment effects. The Egger test is a statistical test for smallstudy effects that may detect increased bias with increasing numbers of trials on the basis of a linear regression model [24, 25]. In this study, publication bias was assessed using the Egger test. $P$ values of $<0.05$ indicated statistical significance. 


\section{Results}

\section{Literature retrieval}

The literature retrieval results and screening process are shown in Fig. 1. A total of 2053 citations were generated from PubMed $(n=742)$, Embase $(n=1418)$, and the Cochrane Library $(n=81)$. Among the articles, 485 duplicate studies and 10 reviews or meta-analyses not related with CHD and case-control studies were excluded. Thus, 45 articles remained after a full-text review. Furthermore, 15 articles were excluded because they did not have the outcome of interest or were duplicate studies. Finally, 30 articles [9-13, 26-50] were selected for the meta-analysis.

\section{Characteristics of the studies}

Table 1 shows the characteristics of the 30 included studies published from 2011 and 2020 and distributed in China, Japan, the United States, and Canada. The sample size of the included studies was 9925 patients (range, 471510 cases), in which 3506 patients (range, 4-503 cases) had AKI. Among the 30 included studies, 10 were prospective cohort studies and 20 were retrospective cohort studies. In addition, 13, 8, and 9 studies used the pRIFLE, AKIN, and KDIGO criteria for AKI diagnosis, respectively. Furthermore, Aydin et al. [11], Lee et al. [35], and Park et al. [41] not only reported the incidence rates in the general population but also stratified them by age.

\section{Assessment of methodological quality}

The evaluation results of the methodological qualities of the included study are shown in Table 2. All the studies provided the source of information, inclusion and exclusion criteria, time period for recruiting patients, completeness of the data collection, and so on. However, information on confounding assessment, missing data handling, and clarifying follow-up was lacking in most of the included studies. Among the 30 included studies, 4 (13.3\%) with scores of 8 were considered high-quality and the remaining 26, with scores between 5 and 7 , were

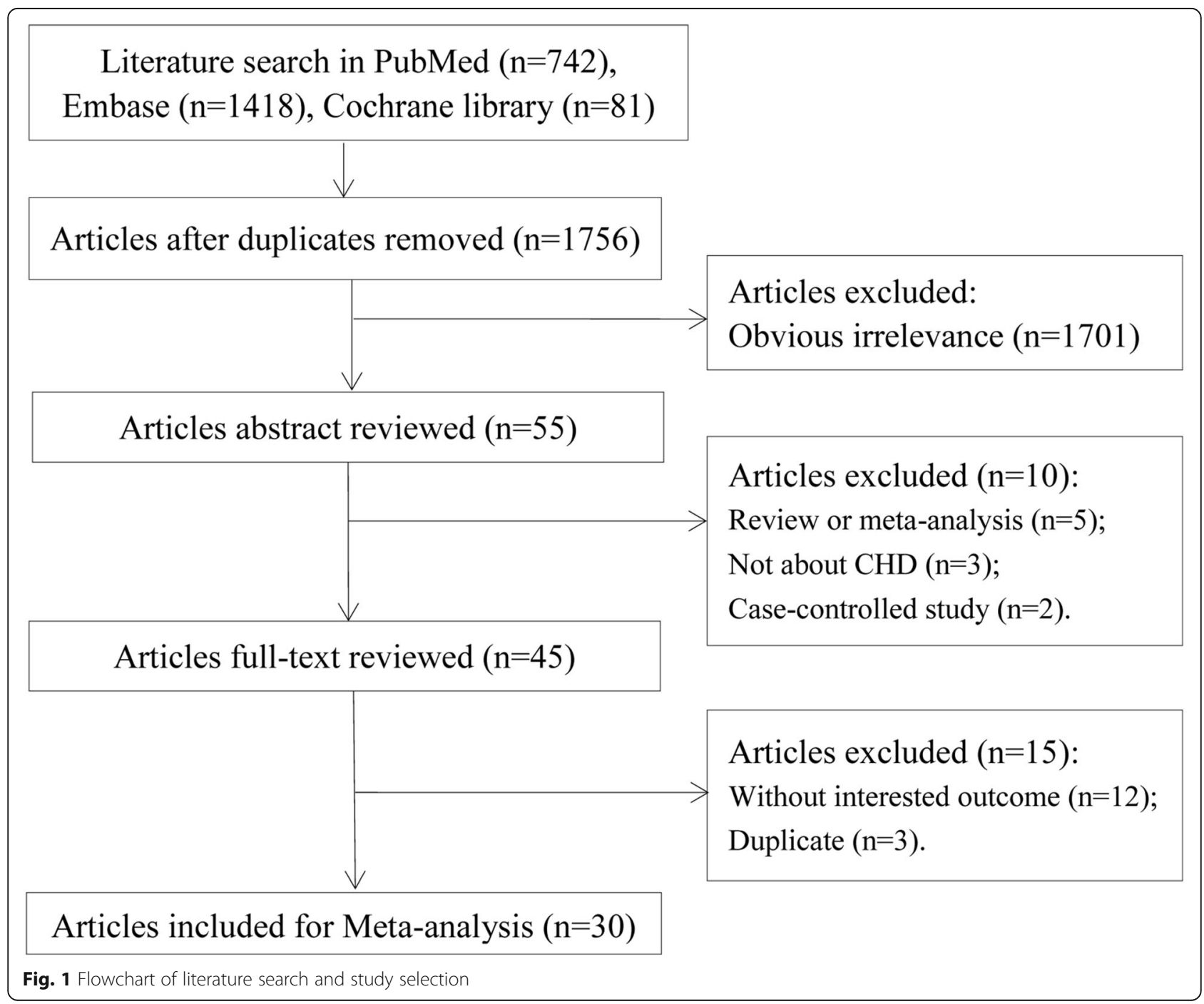


Table 1 Characteristics of the studies included in the meta-analysis

\begin{tabular}{|c|c|c|c|c|c|c|c|}
\hline Study/Year & Area/Design & Type of surgery & Time of recruitment & Criteria of AKI & $n, M / F(\%)$ & Age & AKI (\%) \\
\hline Amini, S 2017 & Iran/PCS & $\mathrm{CS}$ for $\mathrm{CHD}$ & 2013.03-2016.02 & pRIFLE & $519,49.9 / 50.1$ & $<18$ years & $150(28.9)$ \\
\hline \multirow[t]{3}{*}{ Aydin, SI 2012} & \multirow[t]{3}{*}{ USA/RCS } & \multirow[t]{3}{*}{$\mathrm{CS}$ for $\mathrm{CHD}$} & \multirow[t]{3}{*}{ 2006.01-2009.11 } & \multirow[t]{3}{*}{ pRIFLE } & $458,52.4 / 47.6$ & $<18$ years & $234(51.1)$ \\
\hline & & & & & $87,52.9 / 47.1$ & $<1$ month & $53(60.9)$ \\
\hline & & & & & $371,52.3 / 47.7$ & 1 month-18 years & $181(48.8)$ \\
\hline Blinder, JJ 2017 & USA/RCS & $\mathrm{CS}$ for $\mathrm{CHD}$ & 2006.09-2012.05 & AKIN & $799,53.8 / 46.2$ & $0-36 \mathrm{~ms}$ & $289(36.2)$ \\
\hline Fuhrman, DY 2019 & USA/RCS & $\mathrm{CS}$ for $\mathrm{CHD}$ & 2004.01-2015.12 & KDIGO & $699,56.4 / 43.6$ & $18-40$ years & $92(13.2)$ \\
\hline Garcia, RU 2020 & USA/RCS & $\mathrm{CS}$ for $\mathrm{CHD}$ with $\mathrm{CPB}$ & 2012.01-2017.12 & pRIFLE & $149,65.1 / 34.9$ & $14.9(12.7-16.9)$ years & $4(2.7)$ \\
\hline Gil-Ruiz Gil-Esparza 2014 & Spain/RCS & $\mathrm{CS}$ for $\mathrm{CHD}$ with $\mathrm{CPB}$ & $2008.01-2010.12$ & pRIFLE & $409,60.4 / 39.6$ & 1 month-18 years & $107(26.2)$ \\
\hline Hirano, D 2017 & Japan/RCS & $\mathrm{CS}$ for $\mathrm{CHD}$ & 2007.04-2013.08 & pRIFLE & $418,62.0 / 38.0$ & $5.0(2.0-19.0)$ months & $104(24.9)$ \\
\hline Huggins, N 2014 & USA/RCS & $\mathrm{CS}$ for $\mathrm{CHD}$ & 2007.01-2010.11 & AKIN & $113, \mathrm{NR} / \mathrm{NR}$ & $<18$ years & $46(40.7)$ \\
\hline Joffe, R 2018 & Canada/PCS & $\mathrm{CS}$ for $\mathrm{CHD}$ with $\mathrm{CPB}$ & 2013-2015 & KDIGO & $66,51.5 / 48.5$ & 5.9 (4.6-11.5) months & $43(65.2)$ \\
\hline Kim, J 2020 & USA/RCS & $\mathrm{CS}$ for $\mathrm{CHD}$ with $\mathrm{CPB}$ & 2013.04-2018.05 & AKIN & $123,49.6 / 50.4$ & $\geq 18$ years & $52(42.3)$ \\
\hline Kimura, S 2018 & Japan/RCS & $\mathrm{CS}$ for $\mathrm{CHD}$ with $\mathrm{CPB}$ & 2013.12-2017.01 & KDIGO & $521,53.4 / 46.6$ & $<72$ months & $205(39.3)$ \\
\hline Kumar, TK 2016 & USA/RCS & $\mathrm{CS}$ for $\mathrm{CHD}$ with $\mathrm{CPB}$ & $2010.01-2012.12$ & AKIN & $102,55.9 / 44.1$ & $<2$ months & $11(10.8)$ \\
\hline Kwiatkowski, DM 2017 & USA/RCS & $\mathrm{CS}$ for $\mathrm{CHD}$ with $\mathrm{CPB}$ & $2010.01-2013.12$ & KDIGO & $118,50.0 / 50.0$ & $29(21-39)$ years & $42(35.6)$ \\
\hline \multirow[t]{3}{*}{ Lee, SH 2017} & \multirow[t]{3}{*}{ Korea/RCS } & \multirow[t]{3}{*}{$\mathrm{CS}$ for $\mathrm{CHD}$ with $\mathrm{CPB}$} & \multirow[t]{3}{*}{ 2011.04-2011.12 } & \multirow[t]{3}{*}{ pRIFLE } & $135,51.1 / 48.9$ & $<18$ years & $19(14.1)$ \\
\hline & & & & & $13, \mathrm{NR} / \mathrm{NR}$ & $<1$ month & $4(30.8)$ \\
\hline & & & & & $122, \mathrm{NR} / \mathrm{NR}$ & 1 month-18 years & $15(12.3)$ \\
\hline Li, S 2011 & USA/PCS & $\mathrm{CS}$ for $\mathrm{CHD}$ & 2007.07-2009.12 & AKIN & $311,55.0 / 45.0$ & 1 month-18 years & $130(41.8)$ \\
\hline Madsen, NL 2017 & Denmark/PCS & $\mathrm{CS}$ for $\mathrm{CHD}$ & 1990.01-2010.12 & KDIGO & $382,57.1 / 42.9$ & $<14$ years & $127(33.2$ \\
\hline Mah, KE 2018 & USA/RCS & $\mathrm{CS}$ for $\mathrm{CHD}$ & 2010.10-2012.12 & KDIGO & $117,59.8 / 40.2$ & $<30$ days & $66(56.4)$ \\
\hline Meersch, M 2014 & Germany/PCS & $\mathrm{CS}$ for $\mathrm{CHD}$ with $\mathrm{CPB}$ & 2013.07-2013.12 & pRIFLE & $51,72.5 / 27.5$ & $<18$ years & $12(23.5)$ \\
\hline Miklaszewska, M 2013 & Poland/PCS & $\mathrm{CS}$ for $\mathrm{CHD}$ with $\mathrm{CPB}$ & $2006-2009$ & pRIFLE & $47,51.1 / 48.9$ & $0.5-204$ months & $19(40.4)$ \\
\hline \multirow[t]{3}{*}{ Park, SK 2016} & \multirow[t]{3}{*}{ Korea/RCS } & \multirow[t]{3}{*}{$\mathrm{CS}$ for $\mathrm{CHD}$} & \multirow[t]{3}{*}{$2012.01-2012.12$} & \multirow[t]{3}{*}{ KDIGO } & $220,55 / 45$ & 10 days -18 years & $92(41.8)$ \\
\hline & & & & & $60, N R / N R$ & $<1$ month & $29(48.3)$ \\
\hline & & & & & $160, N R / N R$ & 1 month-18 years & $63(39.4)$ \\
\hline Piggott, KD 2015 & USA/RCS & $\mathrm{CS}$ for $\mathrm{CHD}$ & 2010.05-2013.12 & AKIN & $95,50.5 / 49.5$ & $<1$ month & $43(45.3)$ \\
\hline Ricci, Z 2012 & Italy/PCS & $\mathrm{CS}$ for $\mathrm{CHD}$ with $\mathrm{CPB}$ & 2010.06-2011.06 & pRIFLE & $160,55 / 45$ & $<1$ years & $90(56.3)$ \\
\hline Ruf, B 2015 & Germany/PCS & $\mathrm{CS}$ for $\mathrm{CHD}$ with $\mathrm{CPB}$ & $2011.01-2011.08$ & pRIFLE & $59,59.3 / 40.7$ & $<1$ years & $28(47.5)$ \\
\hline Sugimoto, K 2016 & Japan/PCS & $\mathrm{CS}$ for $\mathrm{CHD}$ with $\mathrm{CPB}$ & 2010.07-2012.07 & pRIFLE & $376,58 / 42$ & 1 month-18 years & $243(64.6)$ \\
\hline Tanyildiz, M 2017 & Turkey/RCS & $\mathrm{CS}$ for $\mathrm{CHD}$ & 2009.01-2011.10 & pRIFLE & $137,53.3 / 46.7$ & 1 month-18 years & $84(61.3)$ \\
\hline Taylor, ML 2013 & USA/RCS & $\mathrm{CS}$ for $\mathrm{CHD}$ & $2009.01-2009.12$ & AKIN & $693,53 / 47$ & 6 days-18 years & $104(15)$ \\
\hline Toth, R 2012 & Hungary/RCS & $\mathrm{CS}$ for $\mathrm{CHD}$ & 2004.01-2008.12 & pRIFLE & 1510, NR/NR & $<18$ years & $481(31.9)$ \\
\hline Ueno, K 2020 & Japan/RCS & $\mathrm{CS}$ for $\mathrm{CHD}$ & 2010.05-2018.01 & KDIGO & $81,60.5 / 39.5$ & $<1$ month & $57(70.4)$ \\
\hline Van Driest, SL2018 & USA/RCS & $\mathrm{CS}$ for $\mathrm{CHD}$ & 2008.07-2016.06 & KDIGO & $999,50.0 / 50.0$ & 1 month-18 years & $503(50.4$ \\
\hline Zheng, J 2013 & China/PCS & $\mathrm{CS}$ for $\mathrm{CHD}$ with $\mathrm{CPB}$ & 2010.11-2011.04 & AKIN & $693,53 / 47$ & $<3$ years & $104(15)$ \\
\hline
\end{tabular}

$n$ number of participants; $M$ male; $F$ female; $A K I$ Acute Kidney Injury; $P C S$ prospective cohort study; $R C S$ retrospective cohort study; $C S$ cardiac surgery; $C H D$ congenital heart disease; CPB Cardiopulmonary Bypass; $p$-RIFLE pediatric (Risk, Injury, Failure and Loss, and End-Stage) criteria; AKIN Acute Kidney Injury; KDIGO Kidney Disease Improving Global Outcomes criteria

classified as moderate-quality. Overall, the methodologies of the included studies were of a moderate quality.

Meta-analysis results of AKI in the patients with CHD Thirty studies [9-13, 26-50] reported the incidence rate of AKI. These studies were significantly heterogeneous
$\left(I^{2}=98.169 \%, P<0.001\right)$. The pooled estimated incidence rate was $38.4 \%$ (95\% CI, 32.0-44.7\%; Fig. 2) based on the random-effects model.

Furthermore, the incidence rate of AKI among males was reported in 23 studies. The pooled incidence rate of AKI was 40.0\% (95\% CI, 33.0-47.1\%; Fig. 3a). In addition, 
Table 2 The methodological quality evaluation of included literature based on AHRQ

\begin{tabular}{|c|c|c|c|c|c|c|c|c|c|c|c|c|c|}
\hline Study & Year & $A$ & B & C & $\mathrm{D}$ & $E$ & $\mathrm{~F}$ & G & $\mathrm{H}$ & I & J & K & Total Scores \\
\hline Chen Ya-ke & 2011 & 1 & 1 & 1 & 1 & 1 & 0 & 1 & 0 & 0 & 1 & 0 & 7 \\
\hline Dong Yu-fu & 2005 & 1 & 1 & 1 & 1 & 0 & 1 & 1 & 0 & 0 & 1 & 0 & 7 \\
\hline Blinder, JJ & 2017 & 1 & 1 & 1 & 1 & 0 & 0 & 1 & 0 & 1 & 1 & 1 & 8 \\
\hline Fuhrman, DY & 2019 & 1 & 1 & 1 & 1 & 0 & 1 & 1 & 0 & 0 & 1 & 0 & 7 \\
\hline Garcia, RU & 2020 & 1 & 1 & 1 & 1 & 0 & 0 & 1 & 0 & 0 & 1 & 1 & 7 \\
\hline Gil-Ruiz Gil-Esparza & 2014 & 1 & 1 & 1 & 1 & 0 & 1 & 1 & 0 & 0 & 1 & 0 & 7 \\
\hline Hirano, D & 2017 & 1 & 1 & 1 & 1 & 1 & 0 & 1 & 0 & 0 & 1 & 0 & 7 \\
\hline Huggins, N & 2014 & 1 & 1 & 1 & 1 & 0 & 1 & 0 & 0 & 0 & 1 & 0 & 6 \\
\hline Joffe, R & 2018 & 1 & 1 & 1 & 1 & 1 & 0 & 1 & 1 & 0 & 1 & 0 & 8 \\
\hline Kim, J & 2020 & 1 & 1 & 1 & 1 & 0 & 1 & 0 & 0 & 0 & 1 & 0 & 6 \\
\hline Kimura, S & 2018 & 1 & 1 & 1 & 1 & 1 & 0 & 1 & 0 & 0 & 1 & 0 & 7 \\
\hline Kumar, TK & 2016 & 1 & 1 & 1 & 1 & 0 & 0 & 0 & 0 & 1 & 1 & 0 & 6 \\
\hline Kwiatkowski, DM & 2017 & 1 & 1 & 1 & 1 & 0 & 1 & 1 & 0 & 0 & 1 & 1 & 8 \\
\hline Lee, SH & 2017 & 1 & 1 & 1 & 1 & 1 & 0 & 1 & 0 & 0 & 1 & 0 & 7 \\
\hline $\mathrm{Li}, \mathrm{S}$ & 2011 & 1 & 1 & 1 & 1 & 0 & 0 & 1 & 0 & 0 & 1 & 0 & 6 \\
\hline Madsen, NL & 2017 & 1 & 1 & 1 & 1 & 0 & 0 & 1 & 0 & 0 & 1 & 0 & 6 \\
\hline Mah, KE & 2018 & 1 & 1 & 1 & 1 & 1 & 0 & 1 & 0 & 0 & 1 & 0 & 7 \\
\hline Meersch, M & 2014 & 1 & 1 & 1 & 1 & 0 & 0 & 1 & 0 & 0 & 1 & 0 & 6 \\
\hline Miklaszewska, M & 2013 & 1 & 1 & 1 & 1 & 0 & 1 & 1 & 0 & 0 & 1 & 0 & 7 \\
\hline Park, SK & 2016 & 1 & 1 & 1 & 1 & 0 & 0 & 1 & 0 & 0 & 1 & 0 & 6 \\
\hline Piggott, KD & 2015 & 1 & 1 & 1 & 1 & 1 & 0 & 1 & 0 & 0 & 1 & 0 & 7 \\
\hline Ricci, Z & 2012 & 1 & 1 & 1 & 1 & 0 & 0 & 0 & 0 & 0 & 1 & 0 & 5 \\
\hline Ruf, B & 2015 & 1 & 1 & 1 & 1 & 0 & 0 & 1 & 0 & 0 & 1 & 0 & 6 \\
\hline Sugimoto, K & 2016 & 1 & 1 & 1 & 1 & 0 & 1 & 0 & 1 & 0 & 1 & 0 & 7 \\
\hline Tanyildiz, M & 2017 & 1 & 1 & 1 & 1 & 0 & 0 & 1 & 0 & 0 & 1 & 0 & 6 \\
\hline Taylor, ML & 2013 & 1 & 1 & 1 & 1 & 1 & 0 & 1 & 0 & 0 & 1 & 0 & 7 \\
\hline Toth, R & 2012 & 1 & 1 & 1 & 1 & 0 & 0 & 1 & 0 & 0 & 1 & 0 & 6 \\
\hline Ueno, K & 2020 & 1 & 1 & 1 & 1 & 0 & 0 & 1 & 0 & 0 & 1 & 0 & 6 \\
\hline Van Driest, SL & 2018 & 1 & 1 & 1 & 1 & 0 & 1 & 1 & 0 & 0 & 1 & 1 & 8 \\
\hline Zheng, J & 2013 & 1 & 1 & 1 & 1 & 0 & 0 & 1 & 0 & 0 & 1 & 0 & 6 \\
\hline
\end{tabular}

A: Define the source of information (survey, record review); B: List inclusion and exclusion criteria for exposed and unexposed subjects (cases and controls) or refer to previous publications; C: Indicate time period used for identifying patients; D: Indicate whether or not subjects were consecutive if not population-based; E: Indicate if evaluators of subjective components of study were masked to other aspects of the status of the participants; F: Describe any assessments undertaken for quality assurance purposes (e.g., test/retest of primary outcome measurements); G: Explain any patient exclusions from analysis; H:Describe how confounding was assessed and/or controlled; I: If applicable, explain how missing data were handled in the analysis; J: Summarize patient response rates and completeness of data collection; K: Clarify what follow-up, if any, was expected and the percentage of patients for which incomplete data or follow-up was obtained

23 studies reported the incidence rate of AKI in the female population. The pooled incidence rate was $38.8 \%$ (95\% CI, 31.5-46.0\%; Fig. 3b). However, no significant difference was observed between men and women $(P<0.05)$.

\section{Subgroup analysis}

The subgroup analysis was conducted mainly using the following five aspects: study location, type of surgery, type of cohort, age, and AKI criteria (Table 3). The results of the subgroup analysis showed that the incidence rate of AKI was not significantly different between the subgroups stratified by study location, type of surgery, type of cohort, and criteria of AKI $(P>0.05)$. Notably, age was significantly associated with the incidence rate of AKI $(P=0.002)$. The pooled estimated incidence rates were $54.3 \%$ (95\% CI, 45.2$63.3 \%$ ) at age < 1 month, $41.6 \%$ (95\% CI, 33.5-49.6\%) at age 1 month to 18 years, $29.9 \%$ (95\% CI, 20.9-38.9\%) at age < 18 years, and $30.0 \%$ (95\% CI, 9.60-50.5\%) at age $\geq 18$ years).

\section{Publication bias}

Publication bias was investigated using the Egger test, which revealed a significant publication bias between the 


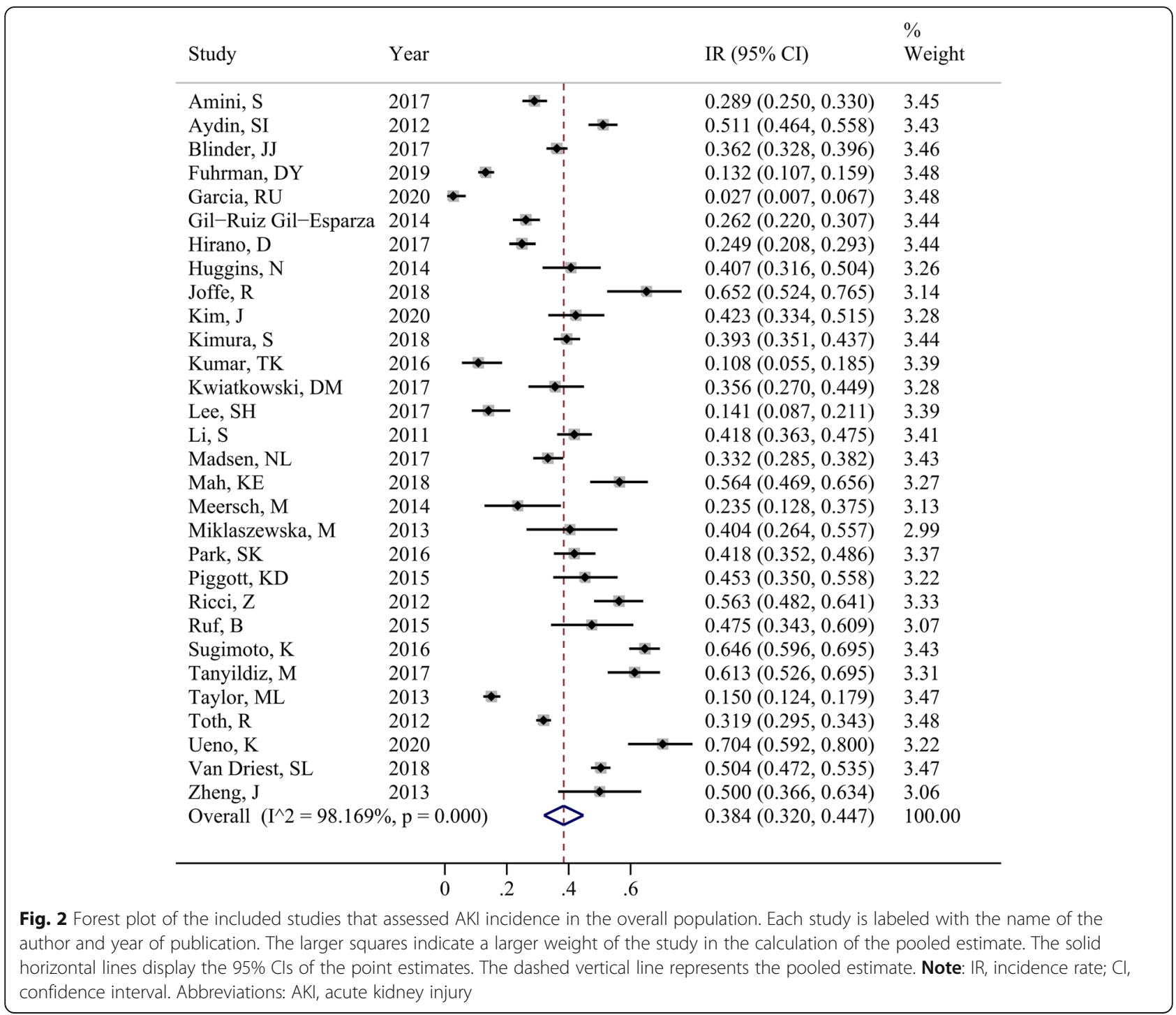

studies $(P=0.007)$. Thus, the trim-and-fill method was applied to verify the stability of the pooled data. After correction by the trim-and-fill method, the incidence rate of AKI was $25.1 \%$ (95\% CI, 18.5-31.7\%). A significant difference was detected between the uncorrected and corrected pooled data $(P=0.004)$, which indicated that the effect of the small sample size may have excessively increased the risk of AKI after cardiac surgery in the patients with $\mathrm{CHD}$.

\section{Discussion}

In this meta-analysis, the pooled incidence rates of AKI in the patients with CHD were $38.4 \%$. However, the incidence rate of AKI showed no significant difference between men and women. In addition, the associations remained when the analyses were restricted to age.

Previous meta-analyses also indicated the incidence rates of AKI in other types of surgeries such as total hip arthroplasty (6.3\%) [15], cardiac transplantation (47.1\%) [16], and liver transplantation (40.8\%) [51]. The pooled incidence rates of $\mathrm{AKI}$ in patients with $\mathrm{CHD}$ ranged from 30 to $45 \%$, which was relatively higher than those in other types of surgery. The difference in surgeryrelated estimates could be attributed to the different clinical landscape and economic burdens. Typically, cardiopulmonary bypass (CPB) time, young age, preoperative AKI, preoperative mechanical ventilation, and perioperative peritoneal dialysis were known as risk factors for AKI development after a congenital heart surgery [26, 52, 53]. Furthermore, accumulating evidence suggests that AKI is a considerable risk factor of poor long-term outcomes, including chronic kidney disease and end-stage renal diseases [54]. Thus, these data indicate the need for better tools in predicting AKI and risk stratification of patients, as well as better preventive strategies. 


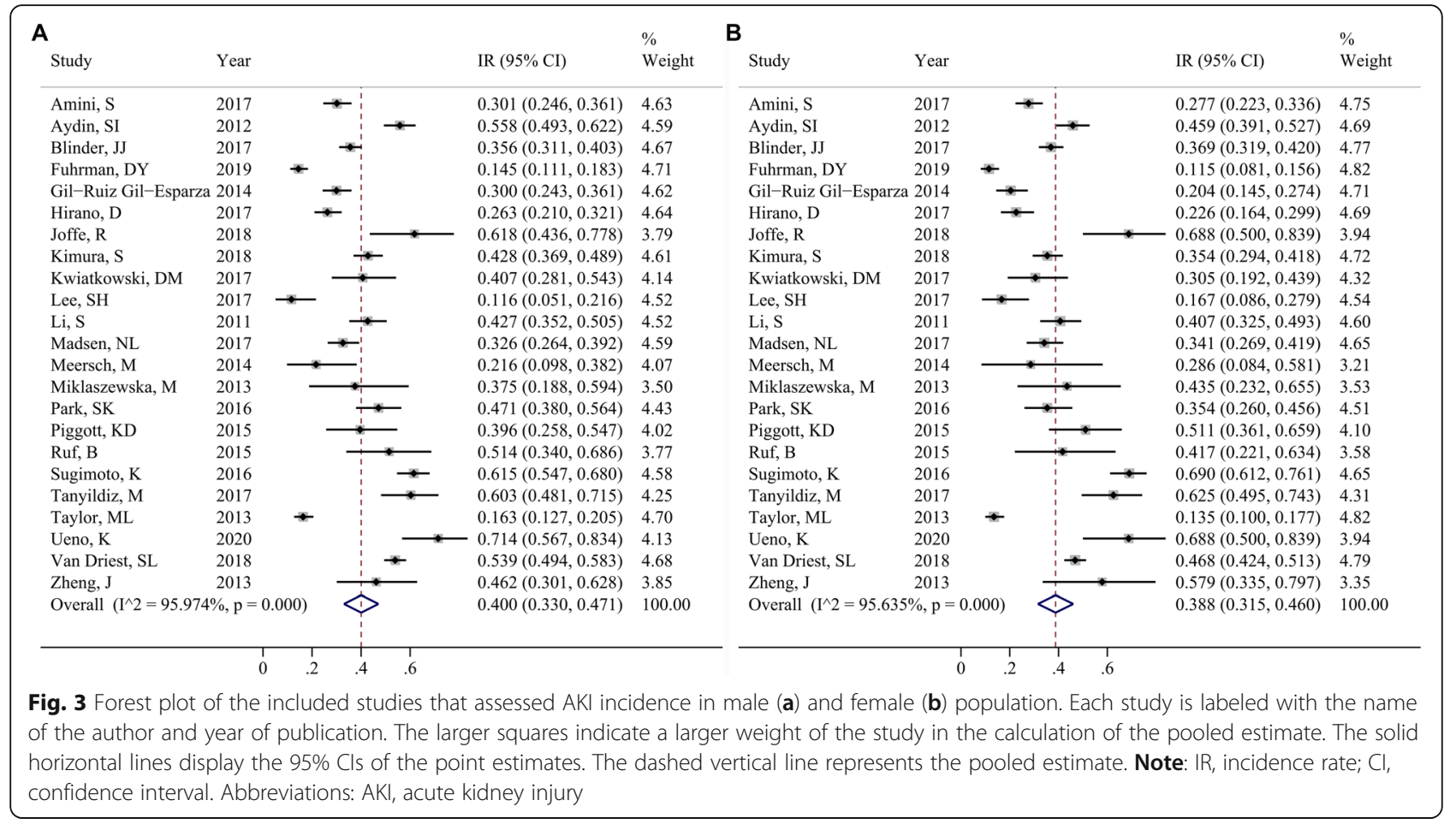

Table 3 Results of subgroup analysis

\begin{tabular}{|c|c|c|c|c|c|}
\hline \multirow[t]{2}{*}{ Outcomes } & \multirow{2}{*}{$\begin{array}{l}\text { No. of } \\
\text { studies }\end{array}$} & \multirow[t]{2}{*}{$\operatorname{IR}(95 \% \mathrm{Cl})$} & \multicolumn{2}{|c|}{ Heterogeneity test } & \multirow{2}{*}{$\begin{array}{l}\text { P- } \\
\text { sub }\end{array}$} \\
\hline & & & $\overline{P 1^{2}(\%)}$ & & \\
\hline Overall & 30 & $0.384(0.320,0.447)$ & $<0.001$ & 98.169 & - \\
\hline Location & & & & & 0.291 \\
\hline Asia & 9 & $0.436(0.319,0.554)$ & $<0.001$ & 97.477 & \\
\hline Western & 21 & $0.361(0.287,0.436)$ & $<0.001$ & 98.268 & \\
\hline Type of surgery & & & & & 0.694 \\
\hline $\mathrm{CS}$ for $\mathrm{CHD}$ & 16 & $0.397(0.324,0.471)$ & $<0.001$ & 98.024 & \\
\hline $\mathrm{CS}$ for $\mathrm{CHD}$ with $\mathrm{CPB}$ & 14 & $0.368(0.242,0.494)$ & $<0.001$ & 98.343 & \\
\hline Type of cohort & & & & & 0.118 \\
\hline Prospective & 10 & $0.451(0.352,0.550)$ & $<0.001$ & 95.038 & \\
\hline Retrospective & 20 & $0.352(0.376,0.427)$ & $<0.001$ & 98.446 & \\
\hline Age & & & & & 0.002 \\
\hline$<1$ month & 6 & $0.543(0.452,0.633)$ & 0.002 & 73.164 & \\
\hline 1 month-18 years & 14 & $0.416(0.335,0.496)$ & $<0.001$ & 96.927 & \\
\hline$<18$ years & 10 & $0.299(0.209,0.389)$ & $<0.001$ & 97.854 & \\
\hline$\geq 18$ years & 3 & $0.300(0.096,0.505)$ & - & - & \\
\hline Criteria of AKI & & & & & 0.471 \\
\hline pRIFLE & 13 & $0.362(0.255,0.470)$ & $<0.001$ & 98.584 & \\
\hline AKIN & 8 & $0.348(0.242,0.453)$ & $<0.001$ & 96.643 & \\
\hline KDIGO & 9 & $0.447(0.318,0.576)$ & $<0.001$ & 98.358 & \\
\hline
\end{tabular}

$P$-sub $P$ value of the difference between subgroups; --, not available. $I R$ incidence rate 
Regarding the relationship between gender and the incidence rate of $\mathrm{AKI}$, the incidence rate of AKI differs among patients with $\mathrm{CHD}$. Li et al. demonstrated that the incidence of AKI was not associated with sex in 130 patients (57 women and 73 men) [36]. Among 82 patients with CHD, the difference between 57 men and 25 women was not significant in early AKI [29]. In accordance with our findings, sex exerts no influence on the incidence rate of AKI.

When stratified by age, our results indicated that the incidence rate of AKI significantly differed. Previous evidence showed that young children were more susceptible to AKI $[55,56]$. A study concluded that the number of patients aged 1-12 months was significantly higher than that of patients aged > 12 months among 92 patients with AKI according to the KDIGO criteria [41]. Meanwhile, another study indicated that among $181 \mathrm{pa}-$ tients with AKI based on the AKIN staging system, 39\% were aged 1 month to 2 years; $54 \%, 2-13$ years; and 7\%, 13-18 years, with significant differences in age [36]. This may be due to the fact that the intrinsically immature neonatal renal tubules may be more vulnerable to ischemic and inflammatory damage during heart surgery [36, 57]. Furthermore, complex cardiac anatomies and surgical repairs in children require longer $\mathrm{CPB}$, which increases the risk of kidney injury [34, 36]. These results were consistent with those of the subgroup analysis in the present study. Consequently, the preliminary speculations that age was significantly associated with the incidence rate of AKI and that the incidence rate of AKI might be greater in patients aged $<1$ month than in those aged 1 month to 18 years, $<18$ years, and $\geq 18$ years were confirmed.

In a subgroup analysis, the difference in location (Asian and Western countries) and type of surgery (coronary stenting [CS] and $\mathrm{CS}+\mathrm{CPB}$ ) showed no significant difference in the incidence rate of AKI. The estimates indicated that incidence rates in patients with AKI from Asian countries, except Japan, were much lower than those reported from Western countries (7$18 \%$ ) [58]. Conversely, the results of this study showed that the research region had no influence on the incidence rate of AKI. These differences may be attributed to the study population, diagnostic testing capabilities, reliable epidemiological data, and available and accessible resources. Moreover, no strong association was observed between $\mathrm{CPB}$ duration and AKI development [26]. By contrast, a meta-analysis indicated that longer $\mathrm{CPB}$ duration was associated with higher risk of AKI development [59]. However, the addition of $\mathrm{CPB}$ could slightly reduce the incidence rate of AKI in the present study, but not statistically significantly. Inconclusive results were obtained because of the different study designs and limited sample size. Thus, further large-sample studies should be conducted to confirm these findings.
Delayed AKI diagnosis leads to increased morbidity and mortality rates. Therefore, patients at high risk of cardiac surgery-associated AKI need timely diagnosis using biomarkers and scoring systems [60]. Treatment is often limited to supportive care such as minimizing fluid overload and avoiding renal toxins, but may ultimately lead to the need for renal replacement therapy $[52,54]$. Moreover, long-term care for AKI patients with CHD is recommended.

The several limitations in the present meta-analysis are as follows: First, the incidence rate of AKI was pooled using different criteria among studies. Owing to the differences in the included literature, the significance of the differences in the incidence of AKI cannot be scientifically compared. Second, because the results of the meta-analysis showed significant heterogeneity, its source could not be determined through a subgroup analysis. Third, the incidence rates of severe AKI requiring dialysis and the mortality of patients with AKI after cardiac surgery were not analyzed because of the limited data. Lastly, the small-study effects induced by the significant publication bias were assessed with the Egger test. The incidence of AKI in patients undergoing cardiac surgery should be verified in higher-quality studies.

\section{Conclusions}

The incidence rate of AKI in patients with $\mathrm{CHD}$ was $38.4 \%$ and significantly associated with age. Moreover, well-designed studies with large sample sizes and higher quality are required to identify preventive strategies for AKI in patients with CHD.

\section{Supplementary information}

Supplementary information accompanies this paper at https://doi.org/10. 1186/s12882-020-02005-2.

Additional file $\mathbf{1}$ Table $\mathbf{S 1}$ The detailed information relating to the retrieval steps and results of PubMed (The retrieval time: 20200424). Table S2 The detailed information relating to the retrieval steps and results of Embase (The retrieval time: 20200424). Table S3 The detailed information relating to the retrieval steps and results of The Cochrane library (The retrieval time: 20200424)

\section{Abbreviations \\ AKl: Acute kidney injury; CHD: Congenital heart disease; Cl: Confidence interval; AKIN: AKI Network criteria; KDIGO: Kidney Disease Improving Global Outcomes criteria}

\section{Acknowledgements}

Not applicable.

\section{Authors' contributions}

TW designed the project and wrote the manuscript.; DL performed the statistical analysis; WS collected the data; QH analyzed and interpreted the data; and ZN revised the paper. All authors read and approved the final manuscript.

\section{Funding}

None. 


\section{Availability of data and materials}

The datasets used and analyzed in the present study are available from the corresponding author upon reasonable requests.

\section{Ethics approval and consent to participate}

Not applicable.

\section{Consent for publication}

Not applicable.

\section{Competing interests}

The authors declare that they have no competing interests.

\section{Author details}

'Department of Environmental Health, Qingdao Centers for Disease Control and Prevention, Qingdao 266033, Shandong, China. ${ }^{2}$ Department of Cardiovascular Surgery, Qingdao Municipal Hospital, No. 5 Donghai Middle Road, Shinan District, Qingdao 266000, Shandong, China.

\section{Received: 26 February 2020 Accepted: 3 August 2020} Published online: 17 August 2020

\section{References}

1. Chelo D, Nguefack F, Menanga AP, Um SN, Gody JC, Tatah SA, Ndombo POK. Spectrum of heart diseases in children: an echocardiographic study of 1,666 subjects in a pediatric hospital, Yaounde, Cameroon. Cardiovasc Diagnosis Ther. 2016;6(1):10.

2. Upadhyay J, Tiwari N, Rana M, Rana A, Durgapal S, Bisht SS. Pathophysiology, etiology, and recent advancement in the treatment of congenital heart disease. J Indian College Cardiol. 2019;9(2):67.

3. Sissman NJ. Incidence of congenital heart disease. JAMA. 2001;285(20): 2579-80.

4. CLV ACZ, Vaartjes I, Uiterwaal CSPM, Langemeijer MM, Koolbergen DR, Hazekamp MG, van Melle JP, Konings TC, Bellersen L, Grobbee DE, Mulder BJM. Surgery in Adults With Congenital Heart Disease. Circulation. 2011; 15(124):2195-201.

5. Parikh CR, Greenberg JH, McArthur E, Thiessen-Philbrook H, Everett AD, Wald R, Zappitelli M, Chanchlani R, Garg AX. Incidence of ESKD and mortality among children with congenital heart disease after cardiac surgery. Clin J Am Soc Nephrol. 2019;14(10):1450-7.

6. Haapanen $H$, Tsang V, Kempny A, Neijenhuis R, Kennedy F, Cullen S, Walker F, Kostolny M, Hsia T-Y, Van Doorn C. Grown-up congenital heart surgery in 1093 consecutive cases: a 'Hidden'Burden of early outcome. Ann Thorac Surg. 2020.

7. Silva ABV, Cavalcante AMRZ, Taniguchi FP. Survival and Risk Factors Among Dialytic Acute Kidney Injury Patients After Cardiovascular Surgery. Braz J Cardiovasc Surg. 2018;33:3.

8. Bellomo R, Kellum JA, Ronco C. Acute kidney injury. Lancet. 2012;380(9843): 756-66.

9. Garcia RU, Balakrishnan PL, Aggarwal S. Does obesity affect the short-term outcomes after cardiothoracic surgery in adolescents with congenital heart disease? Cardiol Young. 2020:1-5.

10. Ueno K, Shiokawa N, Takahashi Y, Nakae K, Kawamura J, Imoto Y, Kawano Y. Kidney disease: improving global outcomes in neonates with acute kidney injury after cardiac surgery. Clin Exp Nephrol. 2020;24(2):167-73.

11. Aydin SI, Seiden HS, Blaufox AD, Parnell VA, Choudhury T, Punnoose A, Schneider J. Acute kidney injury after surgery for congenital heart disease. Ann Thorac Surg. 2012;94(5):1589-95.

12. Taylor ML, Carmona F, Thiagarajan RR, Westgate L, Ferguson MA, Pedro J, Rajagopal SK. Mild postoperative acute kidney injury and outcomes after surgery for congenital heart disease. J Thorac Cardiovasc Surg. 2013;146(1): 146-52.

13. Van Driest SL, Jooste EH, Shi Y, Choi L, Darghosian L, Hill KD, Smith AH, Kannankeril PJ, Roden DM, Ware LB. Association between early postoperative acetaminophen exposure and acute kidney injury in pediatric patients undergoing cardiac surgery. JAMA Pediatr. 2018;172(7):655-63.

14. Bellos I, lliopoulos DC, Perrea DN. Association of postoperative fluid overload with adverse outcomes after congenital heart surgery: a systematic review and dose-response meta-analysis. Pediatr Nephrol. 2020:1-11.

15. Thongprayoon C, Kaewput W, Thamcharoen N, Bathini T, Watthanasuntorn K, Salim SA, Ungprasert P, Lertjitbanjong P, Aeddula NR, Torres-Ortiz A.
Acute kidney injury in patients undergoing Total hip Arthroplasty: a systematic review and meta-analysis. J Clin Med. 2019;8(1):66.

16. Thongprayoon C, Lertjitbanjong $P$, Hansrivijit $P$, Crisafio A, Mao MA, Watthanasuntorn K, Aeddula NR, Bathini T, Kaewput W, Cheungpasitporn W. Acute kidney injury in patients undergoing cardiac transplantation: a metaanalysis. Medicines. 2019:6(4):108.

17. Kellum JA, Levin N, Bouman C, Lameire N. Developing a consensus classification system for acute renal failure. Curr Opin Crit Care. 2002;8(6): 509-14

18. Ueno K, Seki S, Shiokawa N, Matsuba T, Miyazono A, Hazeki D, Imoto Y, Kawano Y. Validation of acute kidney injury according to the modified KDIGO criteria in infants after cardiac surgery for congenital heart disease. Nephrology. 2019;24(3):294-300.

19. Mehta RL, Kellum JA, Shah SV, Molitoris BA, Ronco C, Warnock DG, Levin A. Acute kidney injury network: report of an initiative to improve outcomes in acute kidney injury. Crit Care. 2007;11(2):R31.

20. Kellum JA, Lameire N, Aspelin P, Barsoum RS, Burdmann EA, Goldstein SL, Herzog CA, Joannidis M, Kribben A, Levey AS. Kidney disease: improving global outcomes (KDIGO) acute kidney injury work group. KDIGO clinical practice guideline for acute kidney injury. Kidney Int Supplements. 2012;2(1): $1-138$.

21. A R, C D, A C, al e: Celiac Disease. Rockville (MD): Agency for Healthcare Research and Quality (US),Appendix D. Quality Assessment. http:// wwwncbin/mnihgov/books/NBK35156/?report=classic 2004.

22. Lau J, loannidis J, Schmid C, loannidis JP, Schmid CH. Quantitative synthesis in systematic reviews. Ann Intern Med. 1997;127(9):820-6.

23. Huedo-Medina TB, Sánchez-Meca J, Marín-Martínez F, Botella J. Assessing heterogeneity in meta-analysis: Q statistic or I 2 index? Psychol Methods. 2006;11(2):193-206.

24. Schneck A. Examining publication bias-a simulation-based evaluation of statistical tests on publication bias. PeerJ. 2017;5:e4115.

25. Sterne JA, Gavaghan D, Egger M. Publication and related bias in metaanalysis: power of statistical tests and prevalence in the literature. J Clin Epidemiol. 2000;53(11):1119-29.

26. Amini S, Abbaspour H, Morovatdar N, Robabi HN, Soltani G, Tashnizi MA. Risk factors and outcome of acute kidney injury after congenital heart surgery: a prospective observational study. Ind J Crit Care Med. 2017;21(12):847.

27. Blinder JJ, Asaro LA, Wypij D, Selewski DT, Agus MS, Gaies M, Ferguson MA. Acute kidney injury after pediatric cardiac surgery: a secondary analysis of the safe pediatric euglycemia after cardiac surgery trial. Pediatr Crit Care Med. 2017;18(7):638

28. Fuhrman DY, Nguyen LG, Sanchez-de-Toledo J, Priyanka P, Kellum JA. Postoperative Acute Kidney Injury in Young Adults with Congenital Heart Disease. Ann Thoracic Surg. 2019;107(5):1416.

29. Gil-Ruiz Gil-Esparza MA, Alcaraz Romero AJ, Romero Otero A, Gil Villanueva N, Sanavia Morán E, Rodríguez Sánchez de la Blanca A, Lorente Romero J, Bellón Cano JM. Prognostic relevance of early AKI according to pRIFLE criteria in children undergoing cardiac surgery. Pediatr Nephrol. 2014;29(7):1265-72.

30. Huggins N, Nugent A, Modem V, Rodriguez JS, Forbess J, Scott W, Dimas $W$. Incidence of acute kidney injury following cardiac catheterization prior to cardiopulmonary bypass in children. Catheter Cardiovasc Interv. 2014; 84(4):615-9

31. Joffe R, Al Aklabi M, Bhattacharya S, Cave D, Calleja T, Garros D, Majesic N, Ryerson L, Morgan C. Cardiac surgery-associated kidney injury in children and renal Oximetry. Pediatr Crit Care Med. 2018;19(9):839-45.

32. Kimura S, Iwasaki T, Shimizu K, Kanazawa T, Kawase H, Shioji N, Kuroe Y, Matsuoka $Y$, Isoyama S, Morimatsu H. Hyperchloremia is not an independent risk factor for postoperative acute kidney injury in pediatric cardiac patients. J Cardiothorac Vasc Anesth. 2018.

33. Kumar TS, Allen C, Jerry Spentzas M, Thomas BC, Lindsay SM, Samir JM, Vijaya M, Ballweg M, Jean A, Knott-Craig M, Christopher J. Acute kidney injury following cardiac surgery in neonates and young infants: experience of a single center using novel perioperative strategies. World J Pediatr Congenital Heart Surg. 2016;7(4):460-6.

34. Kwiatkowski DM, Price E, Axelrod DM, Romfh AW, Han BS, Sutherland SM, Krawczeski CD. Incidence, risk factors, and outcomes of acute kidney injury in adults undergoing surgery for congenital heart disease. Cardiol Young. 2017;27(6):1068-75.

35. Lee SH, Kim SJ, Kim HJ, Son JS, Lee R, Yoon TG. Acute Kidney Injury Following Cardiopulmonary Bypass in Children-Risk Factors and Outcomes. Circulation J. 2017;CJ-17:0075 
36. Li S, Krawczeski CD, Zappitelli M, Devarajan P, Thiessen-Philbrook H, Coca SG, Kim RW, Parikh CR. Incidence, risk factors, and outcomes of acute kidney injury after pediatric cardiac surgery-a prospective multicenter study. Crit Care Med. 2011;39(6):1493.

37. Madsen NL, Goldstein SL, Frøslev T, Christiansen CF, Olsen M. Cardiac surgery in patients with congenital heart disease is associated with acute kidney injury and the risk of chronic kidney disease. Kidney Int. 2017;92(3): 751-6.

38. Mah KE, Hao S, Sutherland SM, Kwiatkowski DM, Axelrod DM, Almond CS, Krawczeski CD, Shin AY. Fluid overload independent of acute kidney injury predicts poor outcomes in neonates following congenital heart surgery. Pediatr Nephrol. 2018;33(3):511-20.

39. Meersch M, Schmidt C, Van Aken H, Rossaint J, Görlich D, Stege D, Malec E, Januszewska K, Zarbock A. Validation of cell-cycle arrest biomarkers for acute kidney injury after pediatric cardiac surgery. PLoS One. 2014;9(10): e110865.

40. Miklaszewska M, Pé K, Zachwieja K, Mroczek T, Drozdz D, Sztefko K, Moczulska A, Pietrzyk JA. Serum interleukin 6 levels as an early marker of acute kidney injury on children after cardiac surgery. Adv Clin Exp Med. 2013;22(3):377-86.

41. Park S-K, Hur M, Kim E, Kim WH, Park JB, Kim Y, Yang J-H, Jun T-G, Kim CS Risk factors for acute kidney injury after congenital cardiac surgery in infants and children: a retrospective observational study. PLoS One. 2016;11(11): e0166328.

42. Piggott KD, Soni M, Decampli WM, Ramirez JA, Holbein D, Fakioglu H, Blanco CJ, Pourmoghadam KK. Acute kidney injury and fluid overload in neonates following surgery for congenital heart disease. World J Pediatr Congenital Heart Surg. 2015;6(3):401-6.

43. Ricci Z, Netto R, Garisto C, lacoella C, Favia I, Cogo P. Whole blood assessment of neutrophil gelatinase-associated lipocalin versus pediatricRIFLE for acute kidney injury diagnosis and prognosis after pediatric cardiac surgery: cross-sectional study. Pediatr Crit Care Med. 2012;13(6):66770.

44. Ruf B, Bonelli V, Balling G, Hörer J, Nagdyman N, Braun SL, Ewert P, Reiter K. Intraoperative renal near-infrared spectroscopy indicates developing acute kidney injury in infants undergoing cardiac surgery with cardiopulmonary bypass: a case-control study. Critical Care. 2015;19(1):27.

45. Sugimoto K, Toda Y, Iwasaki T, Shimizu K, Kanazawa T, Muto N, Kawase H, Morimatsu H, Morita K, Maeshima Y. Urinary albumin levels predict development of acute kidney injury after pediatric cardiac surgery: a prospective observational study. J Cardiothorac Vasc Anesth. 2016;30(1):648.

46. Tanyildiz M, Ekim M, Kendirli T, Tutar E, Eyileten Z, Ozcakar ZB, Kavaz A, Yalcınkaya F, Uysalel A, Atalay S. Acute kidney injury in congenital cardiac surgery: pediatric risk-injury-failure-loss-end-stage renal disease and acute kidney injury network. Pediatr Int. 2017;59(12):1252-60.

47. Tóth R, Breuer T, Cserép Z, Lex D, Fazekas L, Sápi E, Szatmári A, Gál J, Székely A. Acute kidney injury is associated with higher morbidity and resource utilization in pediatric patients undergoing heart surgery. Ann Thorac Surg. 2012;93(6):1984-90.

48. Zheng J, Xiao Y, Yao Y, Xu G, Li C, Zhang Q, Li H, Han L. Comparison of urinary biomarkers for early detection of acute kidney injury after cardiopulmonary bypass surgery in infants and young children. Pediatr Cardiol. 2013;34(4):880-6.

49. Hirano D, Ito A, Yamada A, Kakegawa D, Miwa S, Umeda C, Chiba K, Takemasa Y, Tokunaga A, Ida H. Independent risk factors and 2-year outcomes of acute kidney injury after surgery for congenital heart disease. Am J Nephrol. 2017;46(3):204-9.

50. Kim J, Wu A, Grogan T, Wingert T, Scovotti J, Kratzert W, Neelankavil JP. Frequency and Outcomes of Elevated Perioperative Lactate Levels in Adult Congenital Heart Disease Patients Undergoing Cardiac Surgery. J Cardiothoracic Vasc Anesthesia. 2020.

51. Thongprayoon C, Kaewput W, Thamcharoen N, Bathini T, Watthanasuntorn K, Lertjitbanjong P, Sharma K, Salim SA, Ungprasert P, Wijarnpreecha K. Incidence and impact of acute kidney injury after liver transplantation: a meta-analysis. J Clin Med. 2019;8(3):372

52. Webb TN, Goldstein SL. Congenital heart surgery and acute kidney injury. Curr Opin Anaesthesiol. 2017;30(1):105-12.

53. Grams ME, Sang Y, Coresh J, Ballew S, Matsushita K, Molnar MZ, Szabo Z, Kalantar-Zadeh K, Kovesdy CP. Acute kidney injury after major surgery: a retrospective analysis of veterans health administration data. Am J Kidney Dis. 2016;67(6):872-80.

54. Gist KM, Kwiatkowski DM, Cooper DS. Acute kidney injury in congenital heart disease; 2018. p. 101-7.

55. Cerdá J, Lameire N, Eggers P, Pannu N, Uchino S, Wang H, Bagga A, Levin A. Epidemiology of acute kidney injury. Clin J Am Soc Nephrol. 2008:3(3):881-6.

56. Andreoli SP. Acute kidney injury in children. Pediatr Nephrol. 2009;24(2): 253-63.

57. Schwartz GJ, Furth SL. Glomerular filtration rate measurement and estimation in chronic kidney disease. Pediatr Nephrol. 2007;22(11):1839-48.

58. Yang L. Acute kidney injury in Asia. Kidney Diseases. 2016;2(3):95-102.

59. Kumar AB, Suneja M, Bayman EO, Weide GD, Tarasi M: Association Between Postoperative Acute Kidney Injury and Duration of Cardiopulmonary Bypass: A Meta-Analysis 2012, 26(1):0-69.

60. Basu RK, Wang Y, Wong HR, Chawla LS, Wheeler DS, Goldstein SL. Incorporation of biomarkers with the renal angina index for prediction of severe AKI in critically ill children. Clin J Am Soc Nephrol. 2014;9(4):654-62

\section{Publisher's Note}

Springer Nature remains neutral with regard to jurisdictional claims in published maps and institutional affiliations.

\section{Ready to submit your research? Choose BMC and benefit from:}

- fast, convenient online submission

- thorough peer review by experienced researchers in your field

- rapid publication on acceptance

- support for research data, including large and complex data types

- gold Open Access which fosters wider collaboration and increased citations

- maximum visibility for your research: over $100 \mathrm{M}$ website views per year

At BMC, research is always in progress.

Learn more biomedcentral.com/submissions 